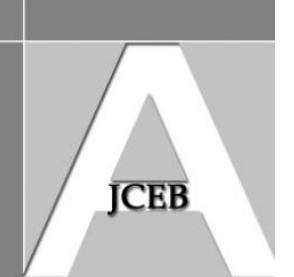

\title{
Book Review \\ Writing a Built Environment Dissertation: Practical Guidance and Examples
}

Peter Farrell, John Wiley \& Sons, 2011, 256 pages, ISBN 9781405198516, Price AUD 44.95, NZD 49.99, USD 37.95, GBP 22.95 EUR 27.60, as eBook USD 30.95 AUD 35.99

Peter Farrell has written a comprehensive and practical introductory guide for first time researchers in the built environment disciplines. As Farrell notes, within the UK system and others, most undergraduates are required to undertake a dissertation and to write a short thesis. In my 20 years' experience final year built environment students are often overwhelmed and intimidated with the seemingly onerous task of what they perceive as 'writing a book'. Their knowledge and understanding of the task that lies ahead and the research process is often limited and a book, such as this, starts by demystifying some of the new and unfamiliar terms associated with research.

Farrell's own extensive experience as a lecturer of research methods and dissertation is evident in the well-defined structure of the text and the useful illustrative examples to demonstrate to readers what is required and involved at each stage. Furthermore the text is well referenced throughout with the key texts which influence the built environment discipline. I particularly liked the sections which highlighted the 'typical mistakes made by students' and first time researchers and think that students will find this useful too. I found the writing style very readable and think that students will find they are able to understand the procedures involved in each stage of the research process without being bogged down in unfamiliar terminology and jargon. Having said this, Farrell does use correct terminology so that readers become familiar and should be able to express themselves accurately using the conventions of research and dissertation writing. The book concludes with a chapter on how to approach the writing of the final chapters and a useful insight into the examiners perspective and experience of reading a thesis.

The appendices are very comprehensive and include checklists and exemplars. One appendix contains information about qualitative analysis and takes the reader through a worked example from the research objectives to the interview questions, transcripts, data analysis and interpretation finishing with a narrative of the data. There are also appendices covering quantitative analysis, where examples clearly illustrate and explain to students how to use and interpret the key statistical tests most frequently applied in this level of research.

Peter Farrell has put a considerable amount of work and time into the text and his direct experience of many years of teaching this subject is apparent in the quality of the guidance and advice given to the readers. Overall this is an informative book that I would adopt, thoroughly recommend and use for teaching dissertation units to students.

Dr Sara Wilkinson

Associate Prof, University of Technology, Sydney 